\title{
Policy Model for National and Academic Digital Collections
}

\author{
Alexandros Koulouris and Sarantos Kapidakis \\ Laboratory on Digital Libraries and Electronic Publishing, Department of Archive \\ and Library Sciences, Ionian University, Plateia Eleftherias, Palaia Anaktora, \\ Corfu 49100, Greece \\ akoul@ionio.gr, sarantos@ionio.gr
}

\begin{abstract}
The access and reproduction policies of the digital collections of fifteen leading academic and national digital libraries worldwide are classified according to factors such as the creation type of the material, acquisition method and copyright ownership. The relationship of these factors and policies is analyzed and quantitative remarks are extracted. We propose a policy model for the digital content of the national and academic libraries. The model consists of rules, supplemented by their exceptions, about which factors lead to specific policies. We derive new policy rules on access and reproduction when different copyright terms are applied. We conclude with findings on policies. Finally, we compare national and academic library policies, showing interesting results that arise on their similarities and differences.
\end{abstract}

\section{Overview of Problem, Methodology and Results}

Libraries are in a transition period from conventional to digital formats and have not yet developed common practices and traditions on policy for digital material. This can prevent cooperation and interoperability in libraries, restricting the usefulness of their services. Conventional policies do not map directly onto digital policies with differences primarily due to the easy duplication properties of the digital material. However, national and academic libraries have well established traditions of cooperation and they play a leading role in the production and dissemination of digital material and in the development of digital libraries.

The access and reproduction policies of the digital collections of thirty-five leading digital libraries worldwide, twenty academic and fifteen national, were examined. Fifteen of them, ten academic and five national, are presented in this poster, those, which are considered to have the most diversified and innovative access and reproduction policies, and are the most active in the area of digital libraries. We were interested in libraries which have collections with various creation types (digitized, borndigital) or content types of material (video, audio etc.), various copyright owners (libraries, individuals, organizations such as publishers etc.), diversified access and reproduction policies and various acquisition methods (license, purchase etc.). To collect the data, we derived information from the websites, in some cases supplemented by personal communication with the libraries and from relevant studies $[1,2]$. The access and reproduction policies of the examined digital collections are classified 
according to factors of creation type, acquisition method and copyright ownership; their relationship is analyzed and quantitative remarks are extracted.

From this analysis, we derive a policy model for the digital content of the national and academic libraries. The proposed policy model is not only comprised of the most common policies - practices that the libraries implement, but also, of new ones that have not been implemented so far, and can offer solutions to problems of access, reproduction and digital content management. The policy model contains rules, supplemented by their exceptions, about which factors lead to specific policies. Due to the differences on policies according to the creation type factor, we divide the policy model onto two separate ones, for the digitized and the digital material respectively, by extracting the relevant conclusions that are valid on each case.

On the two models, we make proposals and recommendations on policies when different copyright terms are applied. For example, what policies can be used when the library has the copyright to the material or when organizations, such as publishers, have it, or when multiple copyright owners exist, or when it varies from item to item? What policy rules apply for onsite (on and off-campus) and offsite access on each case? When and why is the onsite and offsite access the same or diversified? When and why on and off-campus onsite access is different? What combinations of access policies can we face on each case and why? Why is there a distinction between private and commercial reproduction? When and why is fair use doctrine used for private reproduction? Under which factors does the commercial reproduction need written permission and fees, or is prohibited and why?

At the end, we present our findings on policies. Some findings are common for national and academic libraries; for example, the on-campus onsite access is always free, independent of copyright ownership and the creation type of the digital content. In addition, when the library has the copyright of the digital content, the private reproduction is usually provided free with a credit to the source (creator, author) or otherwise mostly under fair use provisions, but the commercial reproduction needs written permission and fees are charged. However, some findings are unique. For example, academic libraries decide the provision of reproduction (private and commercial) on case-by-case basis, when there are copyright uncertainties. On the other hand, national libraries may require fee for the reproduction not for copyright but for preservation reasons; and the copyright fee, which may be required by the copyright owner, is added to the reproduction fee. Finally, national and academic policies are compared and interesting results, on similarities and differences, arise.

\section{References}

1. Meyyappan, N., 2000. A review of the status of 20 digital libraries, Journal of Information Science, 26 (5) pp. 337-355

2. Walters, W.H., 2003. Video media acquisitions in a college library, Library Resources \& Technical Services, 47 (4) pp. 160-170 